\title{
POTENSI PENGEMBANGAN BAWANG PUTIH SEBAGAI KOMODITAS UNGGULAN DI KABUPATEN KARANGANYAR
}

\author{
Yos Wahyu Harinta ${ }^{1)}$, Joko Setyo Basuki ${ }^{2)}$ \\ ${ }^{1,2)}$ Fakultas Pertanian, Program Studi Agribisnis, Universitas Veteran Bangun Nusantara, \\ Jl. Letjend S. Humardani No 1 Jombor Sukoharjo, Telp (0271) 593156, \\ email: yos_wahyu@yahoo.com
}

\begin{abstract}
Abstrak
Sektor pertanian termasuk dalam salah satu sektor dalam pembangunan ekonomi Indonesia yang mendapat prioritas pengembangan. Hal ini dikarenakan Indonesia terkenal sebagai negara agraris yang sebagian penduduknya bermata pencaharian di sektor pertanian. Pembangunan wilayah perdesaan yang berbasis agribisnis telat dikembangkan oleh pemerintah sejak beberapa waktu yang lalu. Salah satu agendanya adalah mengembangkan produk pertanian yang bernilai tinggi untuk meningkatkan pendapatann dan nilai tambah bagi petani. Pembangunan wilayah yang dibatasi oleh anggaran selayaknya diprioritaskan untuk pengembangan sektor-sektor potensial yang mengandung komoditas unggulan. Pemetaan ini perlu dilakukan agar arah pengembangan daerah sesuai dengan tujuan daerah dan nasional. salah satu daerah yang mempunyai keunggulan di bidang pertanian adalah Kabupaten Karanganyar. Pada penelitian ini dilakukan analisis pemetaan komoditas hortikultura sub sayur semusim yang menjadi unggulan pada Kabupaten Karanganyar dengan menggunakan metode analisis Location Quotient (LQ). Hasil yang didapatkan dari sebelas komoditas yang dianalisis, terdapat enam komoditas yang menjadi basis (unggulan) di Kabupaten Karanganyar. Komoditas yang memperoleh nilai LQ tertinggi adalah bawang putih sebesar 7,75. Bawang putih di Kabupaten Karanganyar memang sedang dijadikan salah satu sentra di Provinsi Jawa Tengah. Beberapa kelebihan dan peluang yang menyebabkan pengembangan bawang putih di Kabupaten Karanganyar layak dilakukan adalah kondisi geografis yang mendukung, adanya varietas lokal yang unggul, adanya dukungan dari stakeholder terkait, dan banyak petani yang menanam bawang putih sejak bertahuntahun.
\end{abstract}

Kata kunci: Bawang Putih, Kabupaten Karanganyar, Location Quotient, Pembangunan Wilayah Perdesaan

\begin{abstract}
The agricultural sector is included in one sector in Indonesia's economic development which has priority development. This is because Indonesia is well-known as an agricultural country with a portion of its population making a living in the agricultural sector. The development of rural areas based on agribusiness has been developed late by the government since some time ago. One of the agendas is to develop highvalue agricultural products to increase income and added value to farmers. Regional development which is limited by the budget should be prioritized for the development of potential sectors that contain superior commodities. This mapping needs to be done so that the direction of regional development is in accordance with regional and national goals. one area that has an advantage in agriculture is Karanganyar Regency. In this study an analysis of the seasonal horticultural commodities of sub-vegetables was carried out in Karanganyar Regency using the Location Quotient (LQ) analysis method. The results obtained from eleven commodities analyzed, there are six commodities that are the basis (superior) in Karanganyar Regency. The commodity that obtained the highest $L Q$ value was garlic at 7.75. Garlic in Karanganyar Regency is indeed being one of the centers in Central Java Province. Some of the advantages and opportunities that lead to the development of garlic in Karanganyar Regency are feasible is the supporting geographical conditions, the existence of superior local varieties, the support of relevant stakeholders, and many farmers who plant garlic for years.
\end{abstract}

Keywords: Garlic, Karanganyar Regency, Location Quotient, Rural Area Development 


\section{PENDAHULUAN}

Kebijakan pembangunan wilayah pada dasarnya merupakan keputusan dan intervensi pemerintah, baik secara nasional maupun regional untuk mendorong proses pembangunan daerah secara keseluruhan. Analisis ini sangat penting guna mempercepat pertumbuhan ekonomi daerah, meningkatkan penyediaan lapangan kerja dan penanggulangan kemiskinan pada wilayahwilayah terbelakang. Keseluruhan komponen ini diperlukan untuk dapat meningkatkan proses pembangunan wilayah dan sekaligus untuk meningkatkan kesejahteraan masyarakat setempat (Hidayat, 2017).

Pembangunan wilayah berbasis perdesaan saat ini sedang digalakkan adalah program pengembangan agribisnis. Program ini bertujuan untuk memfasilitasi berkembangnya usaha agribisnis yang mencakup usaha di bidang agribisnis hulu, on farm, hilir dan usaha jasa pendukungnya. Kegiatan pokok program pengembangan agribisnis ini salah satunya adalah pengembangan usahatani dengan komoditas bernilai tinggi, untuk meningkatkan pendapatan dan nilai tambah bagi petani (Kementerian Perencanaan Pembangunan Nasional, 2015).

Di Indonesia pembangunan ekonomi secara umum dibagi dalam sembilan sektor dan diperlukan penetapan prioritas pembangunan karena modal (investasi) yang terbatas. Sektorsektor yang mendapat prioritas tersebut adalah sektor unggulan yang diharapkan dapat mendorong (push factor) sektor-sektor lain untuk berkembang menjadi pendorong utama (prime mover) pertumbuhan ekonomi wilayah. Secara garis besar, sektor ekonomi suatu wilayah dapat dibagi kedalam dua golongan yaitu sektor basis (leading sector) dimana kelebihan dan kekurangan yang terjadi dalam proses pemenuhan kebutuhan tersebut menyebabkan terjadinya mekanisme ekspor dan impor antar wilayah. Artinya industri basis ini akan menghasilkan barang dan jasa baik untuk pasar domestik daerah maupun pasar luar daerah/wilayah. Sedangkan sektor non basis adalah sektor dengan kegiatan ekonomi belum mampu memenuhi pasar di daerahnya sendiri (Baransano, et al., 2016).

Pengembangan usahatani dengan komoditas bernilai tinggi salah satunya adalah bawang putih. Tingginya nilai ekonomi usahatani bawang putih ini dapat dilihat dari jumlah tenaga kerja yang dibutuhkan, biaya yang dikeluarkan, dan pendapatan yang dihasilkan (Sriyadi, 2010).

Bawang putih dianggap sebagai komoditas potensial terutama untuk substitusi impor dan dalam hubungannya dengan penghematan devisa. Demi memenuhi konsumsi dalam negeri, pada tahun 2016 pemeritah Indonesia mengimpor bawang putih dari beberapa negara (mayoritas Cina) sebanyak 448.881 ton atau senilai 448.615.605 US\$ (Wirasti, 2014).

Kementerian Pertanian menargetkan tahun 2019 Indonesia sudah bisa memenuhi kebutuhan benih bawang putih. Hal ini merupakan tahapan penting sebelum mencapai swasembada bawang putih pada tahun 2021. Berbagai varietas lokal maupun impor yang adaptif seperti Lumbu Hijau, Lumbu Kuning, Lumbu Putih, Sangga Sembalun, Tawangmangu Baru dan Great Black Leaf (GBL) asal Taiwan terus dikembangkan sebagai bahan produksi benih.

Penelitian ini bertujuan untuk: a) mengidentifikasi dan menganalisis sektor potensial yang ada pada komoditas hortikultura, b) mengetahui apakah komoditas bawang putih termasuk komoditas unggulan dan c) merumuskan kebijakan pengembangan berdasarkan kebijakan-kebijakan daerah.

\section{METODE PENELITIAN}

Pengumpulan data dilakukan melalui survey primer dan survey sekunder. Survey primer diperoleh dari hasil pengamatan atau observasi lapangan secara langsung, kuesioner serta wawancara. Survey sekunder terdiri dari survey instasional dan survey literatur. Survey instasional dilakukan pada instansi yang memiliki relevansi dengan penelitian, yaitu BAPPEDA dan Dinas Pertanian Tanaman Pangan dan Hortikultura 
Kabupaten Karanganyar. Survey literatur dilakukan dengan meninjau isi dari pustaka yang sesuai dengan penelitian, diantaranya berupa buku, hasil penelitian, artikel dan dokumen tata ruang.

\subsection{Location Quotient}

LQ merupakan salah satu alat sederhana yang biasa digunakan dalam model ekonomi basis sebagai langkah awal untuk memahami sektor kegiatan yang menjadi pemicu pertumbuhan. LQ mengukur konsentrasi relatif atau derajat spesialisasi kegiatan ekonomi melalui pendekatan perbandingan.

$$
L Q=\frac{V i k / V k}{V i p / V p}
$$

Keterangan:

Vik = Nilai produksi komoditas di Kabupaten Karanganyar

Vk $=$ Total nilai produksi seluruh komoditas di Kabupaten Karanganyar

Vip = Nilai produksi komoditas di Provinsi Jawa Tengah

$V p=$ Total nilai produksi seluruh komoditas di Provinsi Jawa Tengah

Hasil perhitungan akan menunjukkan bahwa suatu komoditas tergolong basis akan mendapatkan nilai $L Q>1$; komoditas non basis dengan nilai $L Q<1$; dan komoditas hortikultura yang swasembada dengan nilai $L Q=1$ (Dewi dan Santoso, 2013).

\section{HASIL DAN PEMBAHASAN}

\section{A. Analisis Location Quationt (LQ)}

Hasil perhitungan analisis LQ untuk komoditas hortikultura sub sayuran semusim di Kabupaten Karanganyar dalam kurun waktu tahun 2012-2016 dapat teridentifikasi komoditas yang tergolong basis dan non basis pada Tabel 1. Jenis sayur semusim yang dimasukkan dalam analisis $L Q$ adalah sayur semusim yang memiliki data lengkap baik di tingkat kabupaten maupun di tingkat provinsi. Hal ini dikarenakan dasar dari perhitungan nilai LQ adalah adalah produksi hortikultura di Kabupaten Karanganyar dibandingkan dengan Provinsi Jawa Tengah. Hasil analisis LQ lebih dari 1 berarti bahwa komoditas tersebut merupakan komoditas unggulan (basis).
Berdasarkan Tabel 1 dapat terlihat bahwa dari 11 komoditas yang di analisis:

1. Terdapat 6 komoditas yang bernilai $L Q>1$ yang berarti tergolong dalam komoditas basis (dapat memenuhi kebutuhan lokal dan dapat di ekspor ke luar daerah). Komoditas basisnya adalah bawang putih, wortel, sawi, buncis, kacang panjang dan terong;

2. Ada 5 komoditas yang bernilai $L Q<1$, yang termasuk dalam komoditas non basis, yaitu kubis, tomat, cabai, bawang merah, dan kentang.

Berdasarkan hasil analisis terlihat bahwa nilai LQ komoditas bawang putih menjadi yang tertinggi yakni 7,75 ; kemudian berturut-turut wortel $(5,25)$; sawi $(2,70)$; buncis $(1,57)$; kacang panjang $(1,29)$; dan terong $(1,02)$.

\section{B. Kebijakan Pengembangan Komoditas Unggulan}

Dalam dokumen Rencana Tata Ruang Wilayah Kabupaten Karanganyar Tahun 20132032, terdapat rencana pengembangan komoditas unggulan antara lain sebagai berikut:

1. KSK bidang pertumbuhan ekonomi meliputi:

a. Kawasan yang berpotensi menjadi kegiatan perekonomian tinggi meliputi:

1) Kawasan Strategis Kota Colomadu

2) Kawasan Strategis Kota Jaten

3) Kawasan Strategis Kota Karanganyar

4) Kawasan Strategis Tawangmangu

3. Kawasan yang berfungsi sebagai ketahanan pangan/pertanian basah meliputi:

1) Kawasan Strategis Agropolittan Sukuh, Cetho, Tawangmangu, Karangpandan dan Matesih (Suthomadansih)

2) Kawasan Strategis Agropolitan di Mojogedang

3) Kawasan Agropolitan di Jumapolo

2. Pasal 56 (4); I = kawasan hortikultura sebagai penunjang komoditas unggulan di daerah dilakukan dengan memperhatikan besaran suplai dan 
permintaan pasar untuk menstabilkan harga produk; $m$ = lebih mengutamakan komoditas yang memiliki nilai ekonomis tinggi dan memiliki kemampuan pemasaran yang luas terutama ekspor

3. Pasal 56 (9); i = permukiman perdesaan yang berlokasi di pegunungan dikembangkan dengan berbasis perkebunan dan hortikultura, disertai pengolahan hasil, permukiman perdesaan yang berlokasi di dataran rendah, basis pengembangannya meliputi pertanian tanaman pangan perikanan darat, serta pengolahan hasil pertanian.

Tabel 1. Hasil Analisis LQ Produsi (Ku) Sayuran Semusim Kabupaten Karanganyar Tahun 2012-2016

\begin{tabular}{|c|c|c|c|c|c|c|c|c|}
\hline No & Jenis Sayur & 2012 & 2013 & 2014 & 2015 & 2016 & Rerata & Keterangan \\
\hline 1 & Bawang Putih & 2,07 & 11,83 & 15,72 & 11,72 & 27,47 & 7,75 & BASIS \\
\hline 2 & Wortel & 6,82 & 5,16 & 5,95 & 4,84 & 3,53 & 5,25 & BASIS \\
\hline 3 & Sawi & 3,17 & 2,26 & 2,34 & 2,56 & 3,14 & 2,70 & BASIS \\
\hline 4 & Buncis & 1,09 & 1,17 & 1,25 & 2,40 & 2,05 & 1,57 & BASIS \\
\hline 5 & Kacang Panjang & 0,25 & 1,10 & 1,87 & 1,48 & 1,95 & 1,29 & BASIS \\
\hline 6 & Terong & 0,94 & 0,84 & 0,82 & 0,59 & 2,22 & 1,02 & BASIS \\
\hline 7 & Bawang Merah & 0,17 & 0,12 & 0,10 & 0,26 & 0,27 & 0,19 & NON BASIS \\
\hline 8 & Kentang & 0,00 & 0,00 & 0,00 & 0,00 & 0,00 & 0,00 & NON BASIS \\
\hline 9 & Cabai Besar & 0,41 & 0,37 & 0,33 & 0,81 & 1,06 & 0,60 & NON BASIS \\
\hline 10 & Kubis & 0,39 & 0,78 & 0,89 & 0,70 & 0,75 & 0,70 & NON BASIS \\
\hline 11 & Tomat & 0,61 & 0,92 & 1,06 & 0,58 & 0,23 & 0,69 & NON BASIS \\
\hline
\end{tabular}

Sumber: Data Diolah, 2018

\section{Pengembangan Komoditas Bawang Putih di Kabupaten Karanganyar}

Bawang putih (Allium sativum L.) merupakan salah satu jenis dari komoditas hortikultura yang banyak digunakan oleh masyarakat Indonesia sebagai pelengkap bumbu masak. Perkembangan permintaan bawang putih di Indonesia semakin meningkat seiring dengan laju pertumbuhan penduduk, perkembangan ekonomi dan kesadaran masyarakat terhadap kebutuhan gizi. Bawang putih dapat digunakan sebagai obat anti jamur dan bakteri serta dapat menurunkan kadar kolesterol dan mencegah pembekuan darah. Selain itu, bawang putih dapat digunakan untuk pengobatan penyakit hipertensi, hiperkolesterolemia, diabetes, rheumatoid arthritis, demam atau sebagai obat pencegahan arherosclerosis dan sebagai penghambat tumbuhnya tumor (Majewski, 2014).

Tanaman bawang putih yang dibudidayakan di Indonesia kebanyakan di tanam pada dataran tinggi. Oleh karena itu, luas areal penanaman dan produksi bawang putih masih sangat terbatas. Di samping itu, keberagaman genetik bawang putih sangat sempit karena termasuk tanaman yang diperbanyak secara vegetatif (Sutarto, et al., 2004).

Berdasarkan analisis LQ diatas, terlihat bahwa nilai LQ untuk komoditas hortikultura sub sayuran semusim tertinggi adalah bawang putih $(7,75)>1$, sehingga termasuk komoditas basis yang dapat diunggulkan dan dikembangkan di Kabupaten Karanganyar. Bawang putih yang ditanam di Kabupaten Karanganyar merupakan salah satu prioritas daerah pengembangan yang dicanangkan oleh pemerintah Provinsi Jawa Tengah, selain juga Kabupaten Temanggung.

Luas panen bawang putih di Kabupaten Karanganyar mengalami peningkatan dari tahun 2012 sampai tahun 2016. Rata-rata luas panennya selama kurun waktu tersebut adalah 115,60 hektar. Lahan yang digunakan untuk budidaya bawang putih di Kabupaten Karanganyar cukup baik untuk memproduksi bawang putih. Bawang putih di budidayakan di 
beberapa kecamatan di Kabupaten Karanganyar, antara lain: Jatiyoso, Ngargoyoso, Jenawi, dan Tawangmangu. Daerah dengan produksi bawang putih terbesar selama 2012-2016 berada di Kecamatan Tawangmangu, dengan menyumbang hampir 90 persen produksi bawang putih. Kawasan ini berada di pegunungan dengan ketinggian 1000 meter di atas permukaan laut, sehingga cocok untuk budidaya bawang putih.

Produksi dan produktivitas bawang putih di Kabupaten Karanganyar juga cenderung meningkat dari tahun ke tahun. Rata-rata produksi bawang putih adalah 16.143,60 kuintal dengan produktivitas sebesar 139,07 kuintal/hektar. Produktivitas bawang putih skala nasional pada tahun 2017 adalah 8,83 ton/ha sehingga produktivitas rata-rata bawang putih di Kabupaten Karanganyar sudah baik. Daerah penyumbang produksi bawang putih terbesar di Kabupaten Karanganyar terletak di Kecamatan Tawangmangu, pada tahun 2017 sebesar 6,864 kuintal dengan luas panen 48 hektar. Adanya kerja sama dengan beberapa stakeholder seperti pemerintah daerah, perguruan tinggi dan lembaga keuangan membuat perkembangan bawang putih di Kabupaten Karanganyar cukup baik.

Salah satu jenis bawang putih lokal yang merupakan asli dari daerah Tawangmangu, Karanganyar adalah varietas Tawangmangu Baru (TMB) yang mempunyai produktivitas tinggi. TMB resmi terdaftar di Kementerian Pertanian sejak 1 November 1989. Varietas TMB tersebut banyak ditanam di daerah Tegal, Wonosobo, Banjarnegara, Temangung, Magelang, Magetan dan Karanganyar sendiri. Hasil panen bawang putih Tawangmangu Baru sangat baik, umbinya besar-besar, pertumbuhannya bagus dan batangnya kokoh. Varietas TMB dapat dipanen pada umur 110 sampai 140 hari. Tinggi tanaman bisa mencapai 60 sampai $80 \mathrm{~cm}$. Sesuai ditanam di lahan berketinggian diatas $1.000 \mathrm{mdpl}$. Siungnya berwarna putih keunguan. Aromanya sangat kuat sehingga cocok untuk bumbu masakan. Harga bawang putih TMB kering konsumsi berkisar Rp 30 ribu hingga $\mathrm{Rp} 40$ ribu per kilogram. Sementara harga konde basah di tingkat petani sekitar Rp 20 ribu per kilogram.

Penelitian tentang risiko produktif dan keefisienan relatif komoditas bawang putih di Kecamatan Tawangmangu, Kabupaten Karanganyar sudah dilakukan oleh Supriyadi (2010) dengan kesimpulan bahwa petani mau menanam bawang putih karena pendapatan yang diterima cukup besar dengan rata-rata 48.085.778 juta per hektar. Namun, dalam pengembangan budidaya bawang putih yang memilki banyak risiko mayoritas petani masih enggan menanggung risiko. Alasan ini dapat dimengerti karena kebanyakan rumah tangga petani dihadapkan pada dilema ekonomi sentral (Scott, 1977). Kehidupan petani di perdesaan cukup dekat dengan batasan subsisten dan selalu mengalami ketidakpastian cuaca, sehingga petani tidak mampu berkesempatan untuk menerapkan perhitungan keuntungan maksimum dalam berusahatani. Petani akan berusaha menghindari kegagalan dan bukan memperoleh keuntungan yang besar dengan mengambil risiko. Perilaku tersebut dinamakan dengan safety first atau mendahulukan selamat, yang merupakan ciri dasar sebagian besar petani.

\section{SIMPULAN}

Pengembangan kawasan perdesaan yang berbasis agribisnis yang dicanangkan pemerintah salah satunya adalah pengembangan komoditas bernilai ekonomi tinggi. Komoditas bawang putih merupakan komoditas strategis yang bernilai tinggi yang sedang dikembangkan oleh pemerintah untuk mengurangi laju impor dan inflasi yang disebabkan olehnya. Pemerintah menargetkan swasembada bawang putih pada tahun 2033, dengan sasaran pemenuhan kebutuhan konsumsi dalam negeri, penurunan impor dan mandiri bawang putih. Beberapa kawasan di Indonesia menjadi target untuk program tersebut, salah satunya adalah Kabupaten Karanganyar. Hal yang mendasari pemilihan Kabupaten Karanganyar sebagai salah satu sentral bawang putih di Provinsi Jawa Tengah 
adalah kondisi geografis yang mendukung, ketersediaan lahan yang potensial, banyak petani yang menanam selama bertahun-tahun, adanya varietas lokal yang unggul (Tawangmangu Baru) dan adanya dukungan dari stakeholder terkait. Beberapa alasan tersebut didukung dengan hasil penelitian ini yakni bawang putih merupakan komoditas hortikultura sub sayuran semusim yang mempunyai nilai LQ lebih dari 1 yaitu sebesar 7,75 . Artinya bahwa bawang putih yang ditanam di Kabupaten Karanganyar tergolong komoditas basis yang dapat memenuhi kebutuhan daerahnya dan dapat diekspor ke luar daerah. Komoditas bawang putih ini dapat dikembangkan untuk mendukung program pemerintah dengan mengatasi permasalahanpermasalahan yang ada.

\section{DAFTAR PUSTAKA}

Baransano, M A; Putri Eka I K ; Achzani, N A. 2016. Peranan Sektor Unggulan sebagai Salah Satu Faktor dalam Mengurangi Ketimpangan Pembangunan Wilayah di Provinsi Papua Barat. Jurnal Perencanaan Wilayah dan Kota, 27(2): 119-136.

Dewi, Ayu N P dan Santoso, Eko Budi. 2013. Pengembangan Komoditas Unggulan Sektor Pertanian Tanaman Pangan di
Kabupaten Karangasem melalui Pendekatan Agribisnis.

Hidayat, Muhammad. 2017. Analisis Sektor Unggulan dalam Pengembangan Wilayah Kabupaten Kepulauan Meranti. Media Trend, 12(2): 156-167.

Kementerian Perencanaan Pembangunan Nasional. 2015. Rencana Pembangunan Jangka Menengah Nasional 2015-2019. Jakarta.

Majewski, M. 2014. Allium sativum: Fact and Myths Regarding Human Health. J Natl Ins Public Health, 65(1): 1-8.

Sriyadi. 2010. Risiko Produksi dan Keefisienan Relatif Usahatani Bawang Putih di Kabupaten Karanganyar. Jurnal Pembangunan Pedesaan, 10(2): 69-76.

Sutarto, Ismiyat; Nurohma; Dewi, Kumala; Arwin. 2004. Pengaruh Iradiasi Sinar Gamma ${ }^{60} \mathrm{CO}$ terhadap Pertumbuhan Tanaman Bawang Putih (Allium sativum L) Varietas Lumbu Hijau di Dataran Rendah. Risalah Seminar Ilmiah Penelitian dan Pengembangan Aplikasi Isotop dan Radiasi.

Wirasti, Sri. 2014. Analisis Pendapatan dan Kelayakan Usaha Bawang Putih Goreng pada Industri Rumah Tangga Sofie di Kota Palu. e-J. Agrotekbis, 2(5): 500-504. ISSN: 2338-3011. 
Harinta \& Basuki, 2018

Lampiran 1. Luas Panen (Hektar) Komoditas Hortikultura sub Sayur Semusim di Kabupaten Karanganyar Tahun 2012-2016

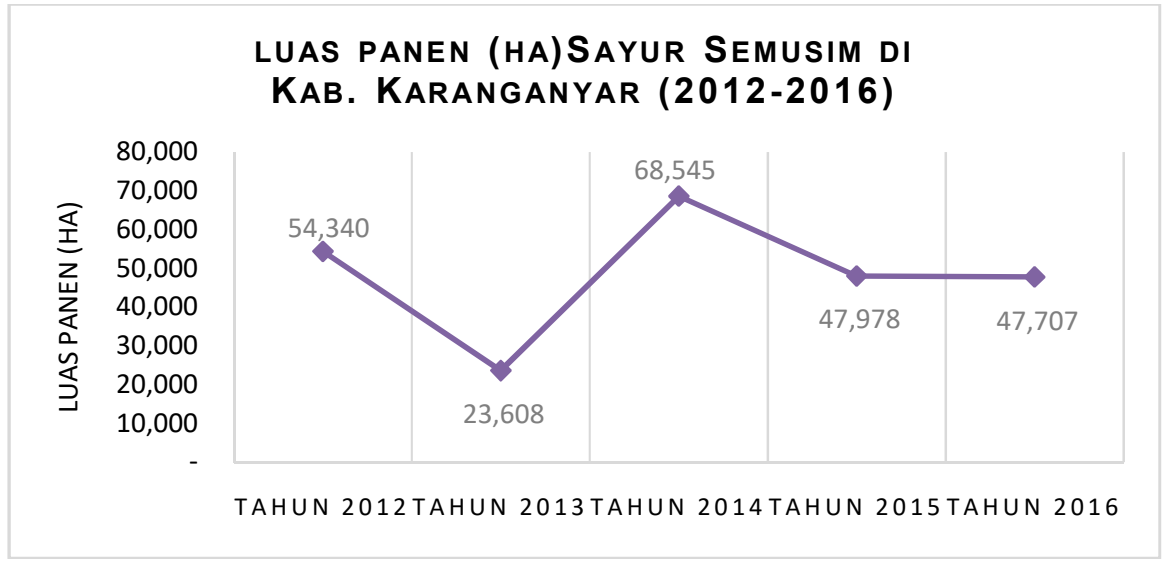

Lampiran 2. Produksi (Kuintal) Komoditas Hortikultura sub Sayur Semusim di Kabupaten Karanganyar Tahun 2012-2016

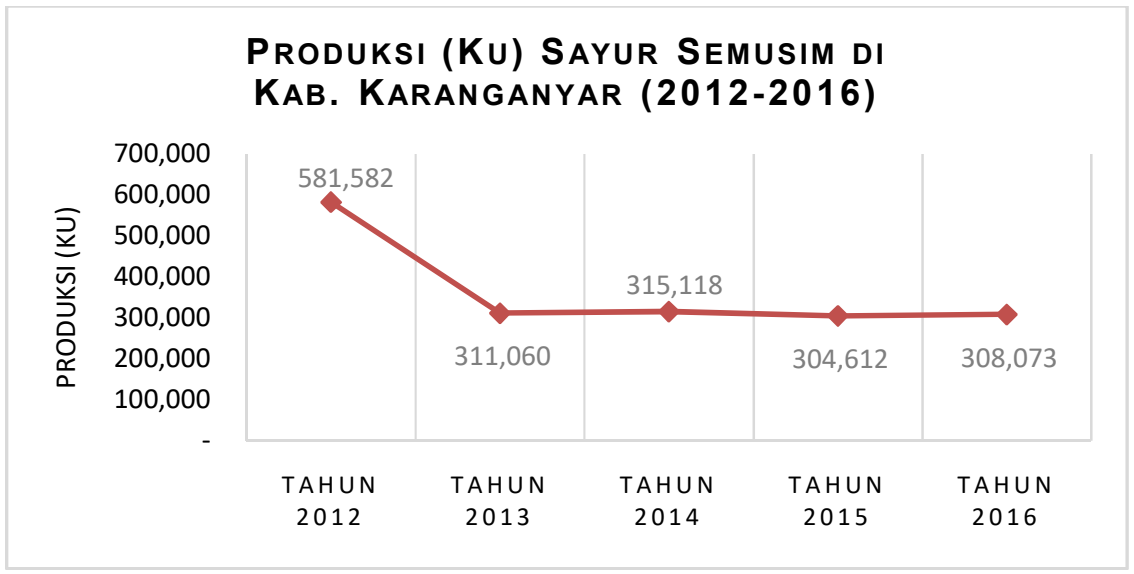

Lampiran 3. Luas Panen (hektar) Bawang Putih di Kabupaten Karanganyar dalam Tahun 2012-2016

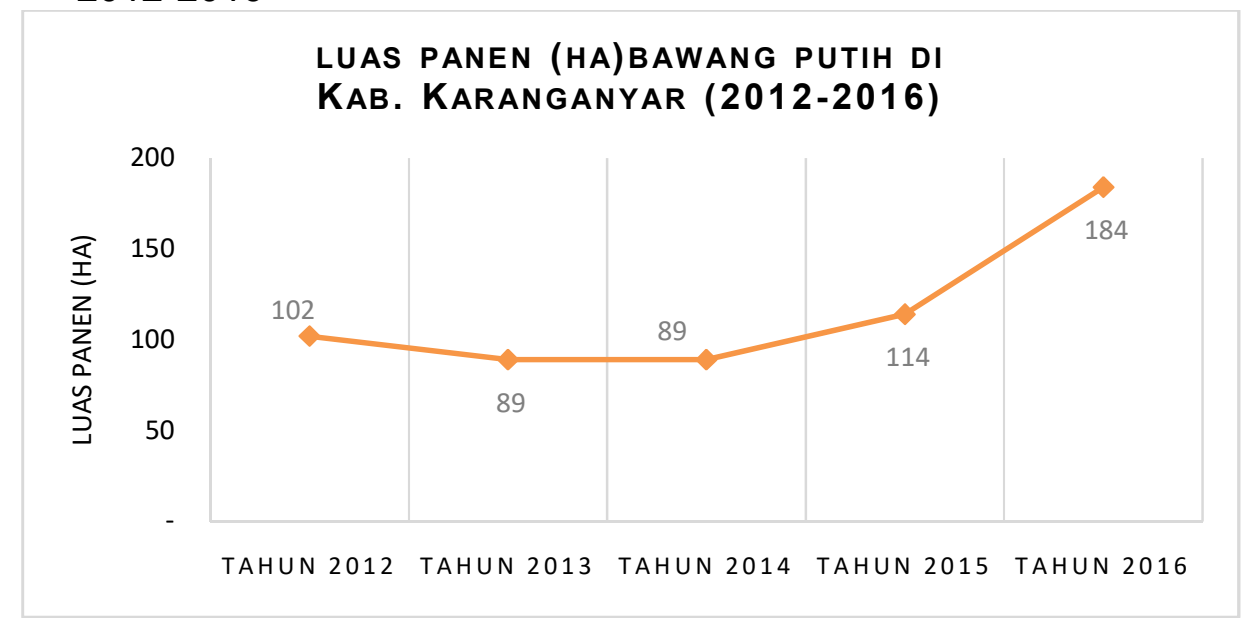


Harinta \& Basuki, 2018

Lampiran 4. Produksi (Kuintal) Bawang Putih di Kabupaten Karanganyar pada Tahun 2012-2016

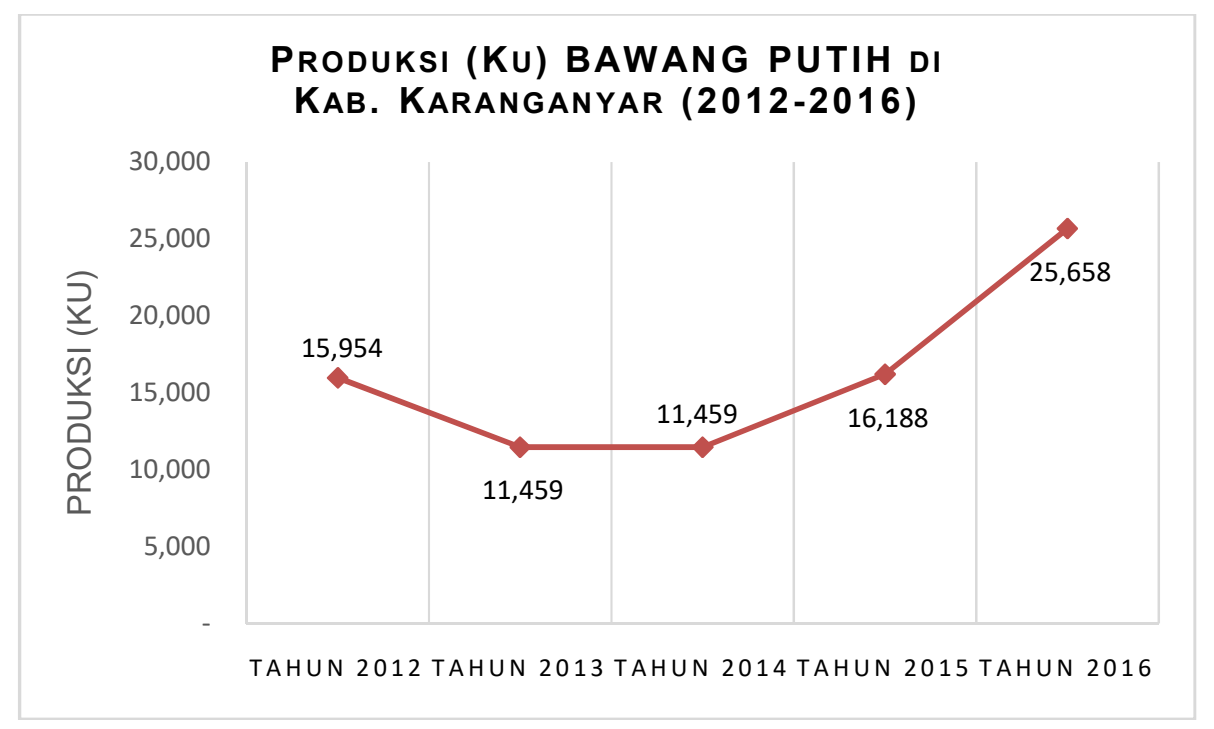

Lampiran 5. Produktivitas (Kuintal/Hektar) Bawang Putih di Kabupaten Karanganyar pada Tahun 2012-2016

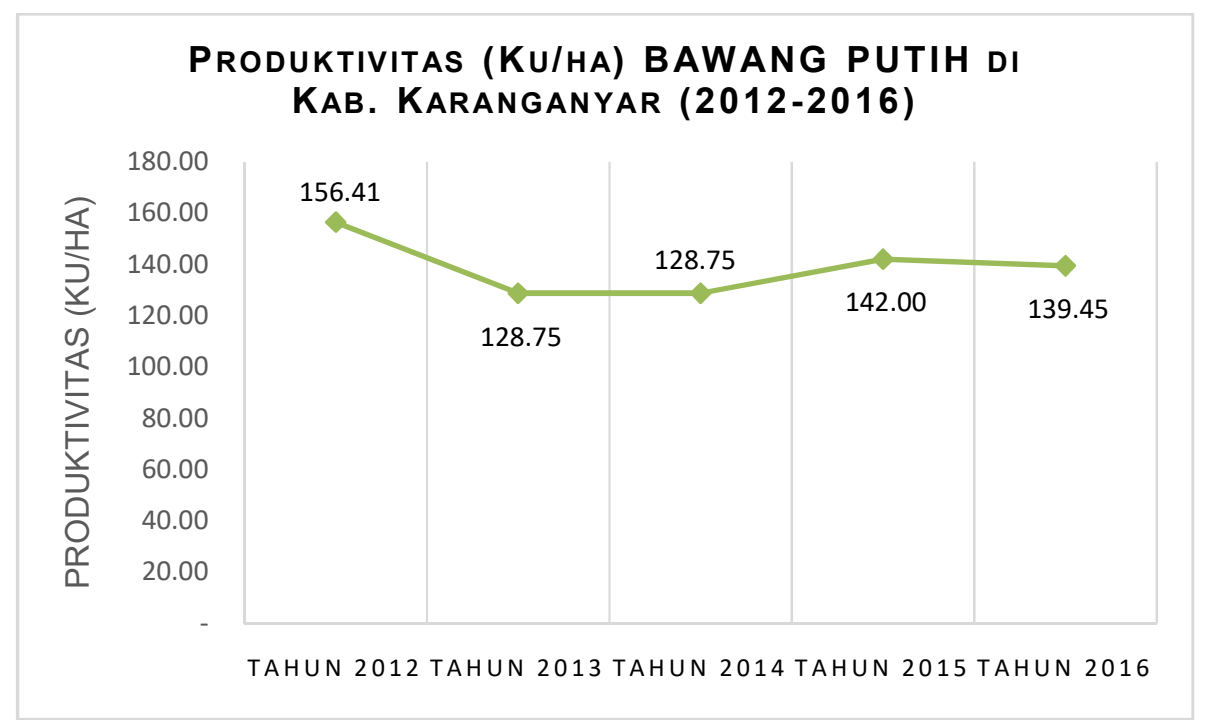

